\title{
The predictive value of selected functional and clinical parameters in stroke rehabilitation
}

\author{
Corresponding author: \\ Piotr Kasprzak \\ Department of Neurological \\ Systemic and Cardiological \\ Rehabilitation, \\ Regional Hospital in Grudziadz, Poland \\ Rydygiera 15/17 \\ 86-300 Grudziądz, Poland \\ Phone: 566414539 \\ E-mail: kasprzakpiotr@tlen.p
}

\begin{abstract}
Introduction. By 2015, the goal of the rehabilitation set by the Helsingborg Declaration 2006, was that more than $70 \%$ of survivors are independant in their activities of daily living by 3 months after the onset of stroke. Material and methods. The research was performed in 109 patients hospitalized in the Department of Systemic Rehabilitation with the Neurological Rehabilitation Unit of the Regional Hospital in Grudziądz, from September 2011 to March 2013. The functional status of patients was assessed on the basis of the modified Rankin scale and Barthel Index, on admission and discharge from the stroke department and rehabilitation unit as well as 3 months after the stroke. The neurological status was assessed using the scale of National Institute of Health Stroke Scale (NIHSS).

Results. Among patients with worse functional status (mRS 3-5 points) symptoms such as aphasia, paresis/plegia and neglect syndrome were more frequent after 3 months. Also their scores on the NIHSS were higher; whereas in the the Barthel Index they were lower. In the multivariant assessment significant predictors of a 3-month prognosis were the clinical scale NIHSS and the functional BI.

Conclusion. Severe paresis or limbs plegia, aphasia and the neglect syndrome are predictors of worse prognosis for the functional status. The NIHSS scale and the BI are comparable, significant predictors of 3-month prognosis.

Key words: rehabilitation, stroke, forecasting, NIHSS, Barthel, Rankin
\end{abstract}

Med Res J 2016; 1 (4): 130-134

\section{Introduction}

According to a definition, stroke is: "a clinical syndrome characterized by the sudden appearance of focal or global dysfunctions of the brain, which, if it do not lead to earlier death, persist longer than 24 hours and do not have a cause other than vascular" [1].

By 2015, the goal of the rehabilitation set by the Helsingborg Declaration 2006, was that more than 70\% of survivors are independent in their activities of daily living by three months after the onset of stroke [2].

In Poland, according to data from 2008, only $19 \%$ of branches provided a comprehensive post-stroke rehabilitation, which secured $38,5 \%$ of the needs in this field [3].

\section{Material and methods}

The study was conducted among 109 patients hospitalized in the Department of Systemic Rehabilitation with the Neurological Rehabilitation Unit of the Regional Hospital in Grudziądz in the Department of Rehabilitation systemic Neurological Rehabilitation Unit of the Regional Hospital in Grudziadz during the period from September 2011 to March 2013. Patients qualified for admission to a branch of rehabilitation and admitted in time to 31 days after discharge from the stroke unit, meeting the criteria of ischemic stroke as defined by the WHO in 1978 [1], at the age of 18-80 years, gave written informed consent participated in the study. Patients were admitted to the department of rehabilitation on the basis of phone qualifications carried out by the patient's neurologist of the stroke unit and the date of admission was set at the same time.

Patients functionally dependent (3-5 pts. in mRS) or functionally independent (0-2 pts. in mRS) with deficits in the range of cognitive and behavioral functions as well as speech and swallowing, were qualified for admission. Patients in serious but stable condition, with inefficiency in circulatory and/or respiratory system or symptoms of active inflammation were not qualified to 
the ward. The subjects were residents of Grudziadz $(34.86 \%)$ and the surrounding smaller towns and rural areas (65.14\%); these proportions correlate with a range of therapeutic activity of RSS in Grudziadz. All patients filled a questionnaire, which collected information on sociodemographic data, diseases and burdens. In the study group within the framework of comprehensive early stroke rehabilitation, individual kinesiotherapy and group therapy, therapy of disturbances of speech disorders, behavioral therapy - cognitive and occupational therapy, were performed according to individual abilities and needs of each patient.

The evaluation of the functional status was carried out on the basis of an assessment by the modified Rankin Scale (mRS) and the 20-point Barthel Index (BI); patients were examined at admission and discharge from the stroke unit, at admission and discharge from the rehabilitation ward, and after 3 months after the illness, during the control visit. Assessment of the neurological status was made based on the severity of paralysis by Lovett scale and evaluation of ataxia in the range of upper and lower limbs; examination was carried out on admission to the rehabilitation unit.

We analyzed sociodemographic clinical factors and functional status of the studied group of patients. For the parts of the analysis, data of 98 participants were used due to the lack of necessary, individual data. Continuous variables are expressed as mean and standard deviation. Categorical variables were expressed as percentages. Comparisons were made based on parametric tests (Student's t-test for continuous variables and chisquare for categorical variables) or their non-parametric equivalents in accordance with the general conditions for their use (U Mann-Whitney test Fischer).

\section{Results}

\section{Period prior to admission to the rehabilitation ward}

The collected data show that the majority of patients started stationary rehabilitation within the 2 weeks after discharge from the stroke unit, but the percentage of rehabilitation deferred for more than 2 weeks is significant (45\% M and K 43\%; NS). Patients who began rehabilitation within 2 weeks after stroke did not differ in terms of functional assessment after 3 months from patients transferred to rehabilitation branch after more than two weeks after stroke (3-5 pts. mRS at $72.73 \%$ among rehabilitated for up to two weeks vs. $69.77 \%$ for period of more than 2 weeks).

\section{Evaluation of functional status during three months of follow-up}

The mean score in the NIHSS at admission to the rehabilitation unit was $8.48 \pm 5.24$ in women and
$9.27 \pm 5.49$ in men $(p=0.459)$. In the $B I$ scoring the difference was statistically significant $(4.93 \pm 6.04 \mathrm{~K} \mathrm{M}$ vs. $2.81 \pm 3.88 ; p=0.042$ ). The efficiency of $0-2$ points in $\mathrm{mRS}$ at 3 months after a stroke was obtained by $28.57 \%$ of the patients $(M 32.08 \%$ and $24.44 \% \mathrm{~K}$; $p=$ 0.4 ), the others obtained, respectively, $3-31.63 \%$, $4-35,71 \%$ and $5-4.08 \%$. Aphasia appeared at baseline in $31.19 \%$ of the respondents (39.66 M K vs. 21.57; $p=0.042$ ) , and the hemispatial neglect at $17.43 \%$ (18.97\% M K vs. $15.69 \%, p=0.652$ ). Hemi/monopareza (-plegia) was present in $51.38 \%$ of the respondents (58.62 M K vs. 43.14; $p=0.107)$. Ataxia was found in $17.43 \%$ of patients ( $M 10.34 \mathrm{~K}$ vs. $25.49 \%, p=0.038$ ). The prevalence of different types of neurological deficit divided by functional state ( $\mathrm{mRS} \leq 2$ pts., And $\mathrm{mRS}>$ 2 pts.). In the group with 0-2 points in the mRS (independent) ataxia was more frequent, while in the group with the number of points in the mRS 3-5 - aphasia, paresis and hemispatial neglect (there was statistically significant difference between the groups with the number of points. $0-2$ and 3-5 mRS; $p<0.05$ ).

In additional breakdown according to gender the dependencies are similar - among men and women with mRS 3-5 - aphasia, paresis and hemispatial neglect are more frequent; however, these symptoms are more frequent in men. As for the whole group - also ataxia is more common among men and women with $\mathrm{mRS}$ 0-2 (probably due to the fact that patients with paresis, ataxia is not defined).

\section{Multivariate analysis}

In the study various schemes of logistic regression were used to develop an optimal model to predict the functional status after 3 months. As the dependent variable scores of $\mathrm{mRS}$ at 3 months follow-up were adopted; result of $0-2$ points was treated as valid, while 3-5 points - as invalid. Due to the number of patients and lack of certain data, in the multivariate analysis 84 observations were included, and thus, the number of independent variables in the model is limited to eight. The selection of the independent variables was due to significant differences identified by $\chi^{2}$ test or Student's t-test between the groups which received mRS 0-2 and 3-5 points. Two alternative models were created. The first model included: gender, age, initial NIHSS score, paresis, ataxia hemispatial neglect, aphasia, education.

The other model included BI instead of NIHSS scoring. The models allow the prediction of patients' dependence by 3 months after stroke (3-5 pts. mRS). NIHSS scoring (higher score patients = worse prognosis) - model 1, and Bl scoring (lower score patients $=$ worse prognosis) - model 2 , allows prediction in significant manner. Other variables used in the regression were not statistically independent significant predictors of a 3 months prognosis. 
In the study group, more than $40 \%$ of patients underwent deferred rehabilitation i.e. in the period of more than 14 days after discharge from the stroke unit. The functional status of these patients did not differ from patients who were rehabilitated earlier, i.e. during $0-14$ days of discharge.

\section{Discussion}

The study evaluates the values of selected parameters normally marked in the stroke units for the 3-month forecasting results in patients after ischemic stroke.

The first 3 months after ischemic stroke constitute the period covering both the acute and subacute phase. In this period the most important decisions of how to deal with the patient (treatment, rehabilitation, care and realistic goals) are taken. During this period, the most dynamic change in general and functional condition of patient takes place.

In the studies of Joergensen et al., which included 1197 patients, it was found that in $95 \%$ of the surveyed, the improvement took place during 12.5 weeks after the stroke, and in $80 \%$ the best results in ADL functions were achieved in the first 6 weeks [4]. It was also observed that the improvement in the functional status was strongly associated with the initial condition of the patient after a stroke. Patients with mild symptoms at the initial stage, achieved the best functional state in 8.5 weeks, with moderate symptoms - in 13 weeks, and at 17 and 20 weeks, respectively, in patients with severe and very severe symptoms of stroke [4]. Hankey et al. confirmed that the average time of improvement in patients with moderate disability was 3 months (3 pts. in mRS). However, in case of severe stroke $(\geq 3$ pts. in $\mathrm{mRS}$ ) gradual improvement in the performance of activities of daily living and in the range of movement may take from 6 months to up to one and a half year after the stroke. However, the greatest improvement was achieved during the first 6 months [5].

Based on the survey and through the application of multivariate analysis in this study, it was found that significant predictors of 3-month prognosis are both NIHSS and BI scale. This analysis showed that patients with higher scores in NIHSS (those in worse functional status) have worse prognosis. Mean baseline score in NIHSS in dependent patients (3-5 pts. in mRS) 3 months after stroke was almost twice as high in independent patients ( $0-2$ pts. in $\mathrm{mRS})$. This is consistent with the study of Schiemanck et al., 2006 [6]; similarly to the study presented in this manuscript, significant prognostic value of NIHSS prognosis for 3 months was confirmed. In this study, the median was 11 , indicating that in most patients neurological deficits were moderate.
Muir et al., [7] and other authors [8] indicate that the initial result in NIHSS of more than 13, obtained in a stroke unit allows us to foresee adverse 3-month results of functional state (constant care required or death) as compared with a score of 13 or fewer points, and they believe that the initial number of points in the NIHSS allows the best prediction of 3-month results $[7,8]$. However, Lai et al. estimated that the study of functional state, where constant care of the patient and death were not separated, could cause that the results of 13 points is important in the 3-month forecasting of global results, but it is not useful to predict the functional status after 3 months after stroke [9].

The authors report that the value of 7 points in the NIHSS in the initial assessment can be considered as limiting in the scope of forecasting better or worse clinical course in the acute phase of stroke. $45 \%$ of the surveyed patients with a baseline NIHSS score of 7 or fewer achieved full functional capability within 48 hours after the stroke; in patients who had more than 7 points the same applied to $2.4 \%$ of patients [10].

In the study of Kwakkel et al., it was found that results of NIHSS obtained during the first 9 days after a stroke are strongly associated with results of evaluation of efficiency $\mathrm{ADL}$ in $\mathrm{Bl}$ and were found to be important in determining early rehabilitation program [11]. On the basis of conducted research and applied analysis we found that scores in $\mathrm{Bl}$ are also a strong predictor of 3-month prognosis. This analysis showed that patients with a lower score in $\mathrm{BI}$ have worse prognosis. Mean baseline in $\mathrm{BI}$ in dependent patients ( $3-5$ pts. in $\mathrm{mRS}$ ) at 3 months after stroke was 3.03 , and the median -0.00 , while in independent patients (0-2 pts. in $\mathrm{mRS}$ ) it was 7.46 , and the median -7.00 .

This is consistent with the review of publications by Quinn et al. in 2011 [12]. Despite the existing reservations concerning the heterogeneity of the evaluation methodology and the limited sensitivity in case of extreme values (floor and ceiling effects), $\mathrm{Bl}$ is recommended for general use in patients with strokes, and at the same time it is one of the most widely used to assess the functional status after stroke [13]. For years, $\mathrm{BI}$ has been through many modifications [14], but a more comprehensive assessment of quality of life after stroke is Stroke Impact Scale (SIS) developed by Duncan et al. [13].

Defining a favourable results in patients after a stroke using $\mathrm{BI}$ is harder than defining an adverse effect. In various studies, varied values from 50 to 95 were used as a cut-off value [15]. However, in numerous studies concerning the acute phase of stroke, 95 or more points constitute a favourable result [16]. A score below 60 is considered an adverse outcome in BI. In studies with a 20-point $\mathrm{BI}$ scale, independence is defined by obtaining 19 and 20 points [6]. The average score of 
$\mathrm{BI}$ on admission to the stroke unit (version of 20-point scale) was described by the author of this work study as 4.93 for women and 2.81 for men; this difference was statistically significant $(p=0.042)$.

In the study of Schiemanck et al., median in $\mathrm{BI}$ at 6 days after stroke was 8 out of 20 [6]. On the basis of the analysis of the literature of database Medline during the period of 1966-2004 conducted by Huybrechts et al., it can be concluded that there is strong evidence of the value of the use of $\mathrm{BI}$ and $\mathrm{mRS}$ as forecasting tools [17]. Those most impaired, according to the $\mathrm{BI}$ assessment, prognosed negatively [4] and have less chance for improvement in daily living activities [18]. It should be noted that the outer modifiable factors (such as appropriate social support) also determine the long-term prognosis and must be taken into account. Other authors point out to the important impact of such disorders as depression on forecasting [19].

Assessment of changes in the functional status on the basis of $\mathrm{BI}$ made within the first 3 days after ischemic stroke (of etiology other than cardiovascular) and after 2 months after the stroke, is more significant predictor of long term survival than the assessment of the initial functional status of the patient [20]. In 2012 Sarker et al. published a study carried out on the basis of the South London Stroke Register, which compared two extended scales assessing ADL-NEADL (Nottingham Extended Activities of Daily Living) and FAl (Frenchay Activities Index) of $\mathrm{Bl}$ in respect of the basic prognostic factors, such as socio-demographic conditions, comorbidities or NIHSS three months after the first stroke.

In this study, the results of $\mathrm{BI}$ were very overvalued (33\%), while in FAl- undervalued (19\%). The results obtained in NEADL were symmetrical (only $4 \%$ of the highest and lowest values). The authors concluded that in the acute phase of stroke, functional state can be predicted on the basis of the results in NIHSS and that the possibility of predicting the functional status in the acute period can reduce unjustified extension of stay in a stroke unit [21].

As shown by the study, in the 3-month observation, functional independence (0-2 pts. in $\mathrm{mRS}$ ) was reached by $28.57 \%$ of patients. In the Kansas City Stroke Study published by Lai and Duncan, also in the 3-month observation, $42.26 \%$ of patients obtained a positive result (0-2 pts. in $\mathrm{mRS}$ ) [22]. No less important is also the result of 3 months observation concerning a positive change (shifted) by at least one point in the $\mathrm{mRS}$. The study's result of 0-2 points on admission to the rehabilitation unit was reached by $3.66 \%$ of patients, and the result of 5 points - by $29.35 \%$ of patients. 3 months after the stroke results were $28.57 \%$ and $4.08 \%$, respectively.

In our study a positive change of at least one point in $\mathrm{mRS}$ was reached by $69.4 \%$ of patients. This result is similar to the values shown in the Kansas City Stroke
Study, in which such a shift was observed in $62 \%$ of patients. However, one should be aware of the limitations of this work; only patients qualified for admission to the rehabilitation unit were included in the study. Worse functional status (3-5 pts.) at 3 months follow-up after ischemic stroke was associated in this study with symptoms such as aphasia, hemospatial neglect, and severe weakness or limbs plegia. In this study, aphasia baseline occurred in $31.19 \%$ of patients $(39.66 \% \mathrm{M}$ vs. F $21.57 \% ; p=0.042)$.

In Nyka's studies conducted in a group of 574 patients, it was found that the lowest functional improvement was achieved by patients with global aphasia and also that this group is characterized by the slowest dynamics of changes. The functional efficiency of this group during the 14-day rehabilitation improved by one point in the ADL Barthel [23]. Similar conclusions were drawn by Gialanella [24]. Hilari in the study published in 2011, which compared patients with and without aphasia, found that patients with aphasia are less active, and their quality of life is worse than patients without aphasia, even if their functional state, welfare and social support are comparable [25]. The severity of aphasia is a strong predictor of long-term mortality and observed during a period of 12 months dependency of patients with aphasia compared with those without aphasia [26]. The hemospatial neglect in this study occurred in $17.43 \%$ of patients ( $M 18.97 \%$ vs. $15.69 \% \mathrm{~K} ; \mathrm{p}=0.652$ ).

The possibility of walking and climbing stairs independently are the most important elements of functional status improvement [27]. It should be noted that elderly patients may have decreased functional abilities resulting from imbalances and severity of degenerative changes in the peripheral joints even prior to stroke, which limit the possibility of obtaining the projected improvement [28].

Based on our review of the literature concerning use of stroke rehabilitation methods and models of improving motor function, it can be concluded that particularly promising techniques are focused on high intensity and repeatability of exercises. The authors point out that most of the available research on the topic related to small groups and had a number of limitations [29].

\section{Conclusions}

In this paper assessment of the impact of selected parameters to predict 3-month results of rehabilitation of patients after ischemic stroke was presented. The study included 109 patients hospitalized in the rehabilitation ward, previously treated in a stroke unit. Final assessment was carried out in the outpatient setting 3 months after a stroke onset. The study lasted from September 2011 to March 2013. The assessment of the 
functional status was carried out based on the modified Rankin scale and a 20-point scale Barthel. The clinical assessment was based on the severity of paralysis by Lovett scale, evaluation of ataxia, diagnosis of aphasia and hemospatial neglect. The NIHSS scale was used as well. After a thorough statistical analysis, the results used for conclusions were obtained. In the 3-month prognosis in patients after ischemic stroke, scores in NIHSS and BI have significance and comparable prognostic value. Patients diagnosed with severe paresis or limbs plegia, aphasia and hemospatial neglect have worse functional outcome at 3 months after stroke, assessed by the modified Rankin Scale.

\section{Conflict of interests: none declared}

\section{References}

1. World Health Organization. Cerebrovascular disorders: a clinical and research classification. World Health Organization, Geneva 1978.

2. Kjellstrom T, Norrwing B, Shatchkute A. Helsingborg Declaration 2006 on European Stroke Strategies. Cerebrovasc Dis, 2007; 23 $231-241$.

3. Sarzyńska-Długosz I, Krawczyk M, Członkowska A. Rozwój wczesne kompleksowej rehabilitacji poudarowej w Polsce - stan obecny i dalsze potrzeby. Neurol Neurochir Pol 2011; 45: 245-251.

4. Jørgensen HS, Nakayama $\mathrm{H}$, Raaschou $\mathrm{HO}$ et al. Outcome and time course of recovery in stroke. Part I: Outcome, Part II: Time course of recovery. Arch Phys Med Rehabil 1995; 76: 399-412.

5. Hankey GJ, Spiesser J, Hakimi Z et al. Rate, degree and predictors of recovery from disability following ischemic stroke. Neurology 2007 68: $1583-1587$

6. Schiemanck SK, Kwakkel G, Post MWM et al. Predicting long-term independency in activities of daily living after middle cerebral artey stroke. Does information from MRI have added predictive value compared with clinical information? Stroke 2006; 37: 1050-1054.

7. Muir KW, Weir CJ, Murray GD et al. Comparison of neurological scales and scoring systems for acute stroke prognosis. Stroke 1996; 27: $1817-1820$

8. Rundek T, Chen X, Hartmann A et al. Stroke syndrome as a predictor of nursing home placement: The Northern Manhattan Stroke Study. Stroke 1998; 29: 321

9. Lai SM, Duncan PW, Keighley J. Prediction of functional outcome after stroke. Comparison of the Orpington Prognostic Scale and the NIH Stroke Scale. Stroke 1998; 29: 1838-1842.
10. DeGraba T, Halenbeck JM, Pettigrew KD et al. Progression in acute stroke: value of the initial NIH Stroke Scale Score on patient stratification in future trials. Stroke 1999; 30: 1208-1212.

11. Kwakkel G, Veerbeek JM, van Wegen EE et al. Predicitive value of the NIHSS for ADL outcome after ischemic hemispheric stroke: does timing of early assessment matter? J Neurol Sci 2010; 294: 57-61

12. Quinn TJ, Langhorne P, Stott DJ. Barthel Index for stroke trials: development,properties and application. Stroke 2011; 42: 1146-1151.

13. Duncan PW, Lai SM, Bode RK et al. Glycine Antagonist in Neuroprotection Americans Investigators. Rasch analysis of a new stroke specific outcome scale: the Stroke Impact Scale. Arch-Phys Med Rehabil 2003; 84: 950-963.

14. Shah S, Vanclay F, Cooper B. Improving the sensitivity of the Barthel Index for stroke rehabilitation. J Clin Epidemiol 1989; 42: 703-709.

15. Sulter G. Steen C, De Keyser J. Use of the Barthel index and modified Rankin scale in acute stroke trials. Stroke 1999; 30: 1538-1541.

16. Hacke W, Kaste M, Fiechi C. et al.: the Second European-Australasian Acute Stroke Study Investigators. Randomised double-blind placebo-controlled trial of thrombolytic therapy with intravenous alteplase in acute ischemic stroke (ECASS II). Lancet 1998; 352: 1245-1251.

17. Huybrechts KF, Caro JJ. The Barthel Index and modified Rankin Scale as prognostic tools for long term outcomes after stroke: a qualitative review of the literature. Curr Med Res Opin 2007; 23: 1627-1636.

18. Franchignoni FP, Tesio L, Ricupero $C$ et al. Trunk control test as an early predictor of stroke rehabilitation outcome. Stroke 1997: 28: 1382-1385.

19. Suenkeler $I H$, Nowak M, Misselwitz $B$ et al. Timecourse of health-related quality of life as determined 3, 6 and 12 months after stroke. Relationship to neurological deficit, disability and depression. J Neurol 2002: 249: 1160-1167.

20. Pan SL, Wu SC, Lee TK et al. Reduction of disability after stroke is a more informative predictor of long-time survival than initial disability status. Disabil Rehabil 2007; 29: 417-423.

21. Sarker SJ, Rudd AG, Douiri A et al. Comparison of 2 extended activities of daily living scales with the Barthel Index and predictors of their outcomes: cohort study within the South London Stroke Register (SLSR). Stroke 2012; 43: 1362-1369.

22. Lai SM., Duncan PW. Stroke recovery profile and the Modified Rankin assessment. Neuroepidemiology 2001; 20: 26-30.

23. Nyka WM. Ocena czynników ryzyka, funkcji motorycznych i sprawności ogólnej u pacjentów z afatycznymi zaburzeniami mowy w ostrym okresie udaru niedokrwiennego mózgu. Rozprawa habilitacyjna. Ann Acad Med Gedan 2001; 31 (suppl.): 1-170.

24. Gialanella B. Motor function and functional capacity in hemiplegia with global aphasia after rehabilitation. Clin Ter 2001; 152: 291-297.

25. Hilari K. The impact of stroke: are people with aphasia different to those without? Disabil Rehabil 2011; 33: 211-218.

26. Tsouli S, Kyritsis AP, Tsagalis G et al. Significance of aphasia after first-ever acute stroke: impact on early and late outcomes. Neuroepidemiology 2009; 33: 96- 102 .

27. Jorgensen HS, Nakayama H, Reith J et al. Stroke recurrence: predictors, severity and prognosis. The Copenhagen Stroke Study. Neurology 1997; 48: 891-895

28. Wade DT, Hewer RL, David RM et al. Aphasia after stroke: natural history and associated deficits. J Neurol Neurosurg Psychiatry 1986; 49: 11-16.

29. Langhorne $P$, Coupar F, Pollock $A$. Motor recovery after stroke: a systematic review. Lancet Neurol 2009; 8: 741-754. 